\section{Social change affects Antarctic priorities}

New research priorities will arise for Antarctic science as a result of climate change and possible tensions between conservation and resource utilization. These priorities are not captured in the Scientific Committee on Antarctic Research's Antarctic and Southern Ocean Horizon Scan (see M. C. Kennicutt et al. Nature 512, 23-25; 2014).

Over the next 20 years, the climate debate is likely to shift towards mitigation and adaptation strategies to offset economic, environmental and social impacts. This shift will prioritize efforts to improve forecasts of the most important elements of the scale, nature and consequences of climate change, and will compel research into potentially highrisk adaptation options such as geo-engineering.

By 2034, the Antarctic Treaty System will probably comprise an increased membership, with internal dynamics driven by parties' priorities. There will be more speculation on resource extraction in the lead up to 2048 , which is the earliest juncture at which the indefinite ban on mining under the Madrid Protocol on Environmental Protection to the Antarctic Treaty can be reviewed. Fuelling speculation about exploitation will be a probable increase in ice-free rock, easier access to Antarctica with reductions in seasonal sea ice, and new technologies and drivers for exploration, extraction and visitation. This trend is already evident in the Arctic.

In the Southern Ocean, an expanding krill fishery responding to a growing human population will test the precautionary management regimes that account for dependent predators such as whales, seals and penguins. Science will need to support sustainable fishery models that integrate the ecological consequences of krill catches with those of climate change.

Adding the social dimension to Kennicutt and colleagues' Horizon Scan in our view reprioritizes some of their pressing questions, as well as raising new and important ones. Nick Gales Australian Antarctic Division, Hobart, Australia. nick.gales@aad.gov.au

Phil Trathan British Antarctic Survey, Cambridge, UK. Anthony Worby Antarctic Climate and Ecosystems Cooperative Research Centre, Hobart, Australia.

\section{Intensive dairy farms becoming greener}

I disagree with some of the assertions made by Mark Eisler and colleagues about how to provide a growing human population with high-quality protein from limited arable land (see M. C. Eisler et al. Nature 512, 371; 2014). Their conjecture that cutting animal productivity by $20 \%$ would result in $80 \%$ better welfare and environmental impact is particularly unrealistic.

On the contrary, milk production is being sustainably intensified by effective management of high-yielding herds. Dairy cows have become more productive through genetic selection and better nutrition, housing and health, with a concomitant drop of $63 \%$ in greenhouse-gas emissions per unit of milk produced (J. L. Capper et al. J. Anim. Sci. 87, 2160-2167; 2009).

Typically, the diet of dairy cows in intensive farming systems is $60 \%$ forage fibre by weight (see go.nature. com/h3w7yy). Feeding these cows grain does not divert an equivalent mass of food away from humans, because the concentration of protein and other nutrients in milk surpasses that in grain. The male calves of Holstein dairy cows are already used for meat production, and manure is widely used as fertilizer on dairy farms (see go.nature.com/ ebm5a9).

Stephen LeBlanc University of Guelph, Canada.

sleblanc@uoguelph.ca

\section{Research critics to be properly informed}

You highlight social-media activity following publication of our papers on Homo floresiensis (dubbed hobbits), quoting a tweet that dismisses our conclusions as "based seemingly on zilch" (see Nature 512, 235;

2014). Critics of our findings, which question the taxonomic validity of $H$. floresiensis as a separate species, should have at least read the papers and checked the facts.

Our first report (R. B. Eckhardt et al. Proc. Natl Acad. Sci. USA

111, 11961-11966; 2014)

shows that specimen LB1, the individual originally designated as representing $H$. floresiensis, is developmentally abnormal; the second (M. Henneberg et al. Proc. Natl Acad. Sci. USA 111, 11967-11972; 2014) presents a diagnosis of Down's syndrome for LB1.

These interpretations are based on detailed comparative skeletal morphology (see the papers' supplementary information) and on earlier diagnoses of Down's syndrome from skeletons (see, for example, A. Czarnetzki et al. Lancet 362, 1000; 2003; and M. Rivollat et al. Intl J. Paleopathol. 7, 8-14; 2014).

Objectivity is key in controversial fields, particularly when the evidence is so hardwon. Crucial evidence in this case would come from radiocarbon dating of tissue from LB1 and from unrestricted access to the skeletal remains of the other $14 \mathrm{H}$. floresiensis individuals so that their details can be studied independently. Robert B. Eckhardt Pennsylvania
State University, University Park, USA. Maciej Henneberg University of Adelaide, Australia. eyl@psu.edu

\section{Science should boost well-being, not GDP}

To achieve a more socially equitable society in which science benefits everybody, we need structural changes in the way that our economy works to remove the quest for constant growth of gross domestic product (see www. positivemoney.org). Spending billions of dollars on better versions of existing facilities risks entrenching unsustainable and destructive industries, which will not address the global challenges we face (see go.nature.com/ kyamxu).

Consider, for example, the eviction of indigenous communities in parts of the world where increasingly large areas of land are being sacrificed to mining activity - a situation currently facing populations in southeastern Ecuador (see go.nature. com/1mlkki). Furthermore, poverty and ill health are on the rise in affluent countries such as the United Kingdom, despite resource-intensive technologies (see go.nature.com/xznlni).

If science is to serve the public good, we have to shift to more ecosystem-centred systems that also take human rights and well-being into account. Good examples include the farmer field schools set up by the United Nations, engaging farmers in agro-ecological research (see T. MacMillan and T. Benton Nature 509, 25-27; 2014).

Mark A. de Vries Edinburgh, UK. m.a.devries@mail.com

CONTRIBUTIONS

Correspondence may be submitted to correspondence@nature. com after consulting the author guidelines at go.nature.com/cmchno 